\title{
Midbrain Raphe Modulation of Nonphotic Circadian Clock Resetting and 5-HT Release in the Mammalian Suprachiasmatic Nucleus
}

\author{
J. David Glass, Gregory H. Grossman, Laure Farnbauch, and Lisa DiNardo \\ Department of Biological Sciences, Kent State University, Kent, Ohio 44242-0001
}

\begin{abstract}
Serotonin (5-HT) is an important regulator of the mammalian circadian clock of the suprachiasmatic nucleus (SCN); however, critical questions remain concerning the control of serotonergic activity in the SCN and how this relates to the putative clock-resetting actions of 5-HT. Previously, we reported that electrical stimulation of the dorsal raphe nucleus (DRN) or median raphe nucleus (MRN) in hamsters evoked 5-HT release in the SCN. This DRN-stimulated 5-HT release was blocked by systemic injection of 5-HT antagonists, indicating a 5-HT receptor-mediated pathway from the DRN to the SCN. In the present study, targeted injections of the 5-HT $1,2,7$ antagonist metergoline or the selective $5-\mathrm{HT}_{7}$ antagonist DR4004 into the DRN or MRN attenuated DRN-electrically stimulated SCN 5-HT release, supporting a multisynaptic DRN $\rightarrow M R N \rightarrow S C N$ route. Intra-DRN and intra-MRN injections of the $\mathrm{GABA}_{\mathrm{A}}$ antagonist bicuculline significantly stimulated SCN 5-HT release, whereas intra-DRN or intra-MRN injections of the $\mathrm{GABA}_{\mathrm{A}}$ agonist muscimol suppressed this release. The 5-HT release induced by intra-DRN bicuculline was also blocked by co-injection of DR4004. In complementary behavioral trials, SCN 5-HT release associated with a phase-advancing sleep deprivation stimulus at midday was prevented by intra-DRN injection of metergoline. Also, phase-advance shifts induced by novel wheel access at midday were suppressed, but not blocked, by intra-DRN injection of DR4004 or muscimol. These results indicate that $5-\mathrm{HT}_{7}$ and GABAergic receptors of the DRN and MRN regulate behaviorally induced 5 -HT release in the SCN, and that DRN output modulates nonphotic phase-resetting responses.
\end{abstract}

Key words: serotonin; suprachiasmatic nucleus; circadian; raphe; GABA; hamster; behavior; phase resetting

\section{Introduction}

Circadian rhythms in mammals are generated and maintained by a neural clock located within the suprachiasmatic nucleus (SCN) (Rusak and Zucker, 1979; Moore, 1983; Klein et al., 1991). Clock time is synchronized to the light/dark cycle by photic information relayed from the retina to the SCN via the retinohypothalamic tract (Hendrickson et al., 1972; Moore and Lenn, 1972; Pickard, 1982; Youngstrom and Nunez, 1986; Johnson et al., 1988) and by an indirect projection from the intergeniculate leaflet (IGL) (Card and Moore, 1982; Johnson et al., 1989). Projections from the IGL and the midbrain raphe nuclei also convey nonphotic input to the SCN via neuropeptide Y-containing and serotonin (5-HT)-containing projections, respectively (Albers and Ferris, 1984; Biello et al., 1994; Meyer-Bernstein and Morin, 1996; Marchant et al., 1997).

Despite the extensive literature on the action of 5-HT in the $\mathrm{SCN}$, its physiological roles, particularly those related to behavioral phase regulation, remain speculative. For example, there is evidence that 5-HT acts in the SCN to mediate the clock-resetting effects of behavioral stimulation. This includes findings that

Received Dec. 13, 2002; revised April 15, 2003; accepted April 28, 2003.

This work was supported by National Institutes of Health Grant NS35229 to J.D.G. We thank Meiji Seika Kaisha Ltd. (Yokohama, Japan) for supplying DR4004.

Correspondence should be addressed to J. David Glass, Department of Biological Sciences, Kent State University, Kent, 0H 44242-0001. E-mail: Jglass@kent.edu.

Copyright $\odot 2003$ Society for Neuroscience $\quad$ 0270-6474/03/237451-10\$15.00/0
5 -HT agonists applied to the SCN in vitro or in vivo reset circadian phase (Prosser et al., 1990, 1993; Medanic and Gillette, 1992; Challet et al., 1998; Ehlen et al., 2001) and that behavioral phaseresetting manipulations evoke SCN 5-HT release (Dudley et al., 1998; Grossman et al., 2000). Conversely, reports that raphe lesions (Meyer-Bernstein and Morin, 1998), treatment with 5-HT antagonists (Antle et al., 1998), or depletion of 5-HT in the SCN (Bobrzynska et al., 1996) do not block behavioral phase shifting argue against a role of 5-HT in circadian clock resetting.

Critical questions also remain regarding the respective roles of the dorsal raphe nucleus (DRN) and the median raphe nucleus (MRN) in regulating SCN serotonergic activity. Mapping studies reveal that the MRN is the sole source of SCN serotonergic innervation (Vertes and Kocsis, 1994; Meyer-Bernstein et al., 1997; Moga and Moore, 1997). Nevertheless, stimulation of the DRN produces 5-HT-related effects in the SCN, including inhibition of light-induced Fos expression (Meyer-Bernstein and Morin, 1997) and neuronal discharge (Yu et al., 1997), attenuation of light-induced phase shifts (Weber et al., 1998), and 5-HT release (Dudley et al., 1999). These findings, together with the rapheSCN mapping results, suggest that the DRN communicates with the SCN via a multisynaptic interaction through the MRN. This hypothesis is supported by reports that the MRN and DRN are functionally connected (Mokler et al., 2001; Morin and Pace, 2001) and that DRN-electrically stimulated, but not MRNelectrically stimulated, SCN $5-\mathrm{HT}$ release is blocked by $5-\mathrm{HT}$ 
antagonists, indicative of a multisynaptic $\mathrm{DRN} \rightarrow \mathrm{MRN} \rightarrow \mathrm{SCN}$ pathway (Glass et al., 2000). The present experiments were undertaken to characterize this pathway using targeted intra-raphe injections of 5-HT antagonists with electrical and behavioral stimulations. This approach was also used to test the hypothesis that this pathway modulates behavioral phase-resetting responses. Because intra-raphe GABAergic transmission is important for regulating serotonergic activity (Gervasoni et al., 2000), its role in controlling SCN 5-HT release and nonphotic phase resetting was also a major focus of this study.

\section{Materials and Methods \\ Animals}

Adult male Syrian hamsters (Mesocricetus auratus), raised from breeder pairs obtained from Harlan Sprague Dawley (Indianapolis, IN), were used in these studies. These animals were group housed (two to three per cage) in a climate-controlled $\left(20-22^{\circ} \mathrm{C}\right)$ vivarium under a $14 \mathrm{hr}$ light $/ 10$ hr dark photo period (LD) (200-250 lux). Preceding experimentation, animals were individually housed in a circular polycarbonate cage to facilitate microdialysis and brain stimulation procedures. Rodent chow (Prolab 3000; PMI Feeds, St. Louis, MO) and water were provided ad libitum.

\section{Electrical and pharmacological stimulations of the raphe}

Animals received intracranial implants (DRN-stimulating or MRNstimulating electrode, DRN or MRN microinjection cannula, and SCN microdialysis probe) using stereotaxic surgical procedures (head level in a stereotaxic frame) with sodium pentobarbital (Nembutal; $50 \mathrm{mg} / \mathrm{kg}$ ) as anesthetic. A bipolar-stimulating electrode (Plastics One, Roanoke, VA) was aimed at the DRN [anteroposterior $(\mathrm{AP})=-4.7 \mathrm{~mm}$ from bregma; lateral $(\mathrm{L})=+1.7 \mathrm{~mm}$ from midline; horizontal $(\mathrm{H})=-4.8 \mathrm{~mm}$ from dura at a $20^{\circ}$ angle) or MRN (AP $=-4.4 \mathrm{~mm}$ from bregma; $\mathrm{L}=-2.3$ $\mathrm{mm}$ from midline; $\mathrm{H}=-6.8 \mathrm{~mm}$ from dura at a $20^{\circ}$ angle), and a unilateral 24 gauge stainless steel guide cannula (Plastics One) was implanted contralaterally with its tip situated $1 \mathrm{~mm}$ above the DRN $(\mathrm{AP}=$ $-4.7 \mathrm{~mm}$ from bregma; $\mathrm{L}=-1.7 \mathrm{~mm}$ from midline; $\mathrm{H}=-3.8 \mathrm{~mm}$ from dura at a $20^{\circ}$ angle) or MRN ( $\mathrm{AP}=-4.4 \mathrm{~mm}$ from bregma; $\mathrm{L}=$ $-2.3 \mathrm{~mm}$ from midline; $\mathrm{H}=-5.8 \mathrm{~mm}$ from dura at a $20^{\circ}$ angle). A microdialysis probe was targeted at the lateral margin of the SCN $(\mathrm{AP}=$ $0.3 \mathrm{~mm}$ from bregma; $\mathrm{L}=+0.3 \mathrm{~mm}$ from midline; $\mathrm{H}=-8.0 \mathrm{~mm}$ from dura). The implants were secured to the skull by three stainless steel screws and dental acrylic. Experiments were initiated $24 \mathrm{hr}$ after surgery.

For DRN stimulation, constant current (20 min duration at 150 or 500 $\mu \mathrm{A}, 10 \mathrm{~Hz}$ stimulus frequency, and $2.0 \mathrm{msec}$ pulse duration) was delivered to a bipolar electrode from a stimulus isolator (World Precision Instruments, Sarasota, FL) coupled to a Grass S11 stimulator (Grass Instruments, Quincy, MA). Drug injections into the DRN or MRN were undertaken by inserting a 31 gauge injection needle connected by polyethylene tubing to a $10 \mu \mathrm{l}$ Hamilton syringe into the guide cannula with its tip extending $1.0 \mathrm{~mm}$ beyond the end of the cannula. A 31 gauge stylet inserted into the guide cannula was used to maintain patency between injections. Details of microdialysis probe methodology are provided below.

\section{Microdialysis-HPLC}

Procedures for microdialysis probe construction are similar to those of previous studies (Dudley et al., 1998). Concentrically designed probes were constructed from a 26 gauge stainless steel outer cannula (Small Parts, Miami, FL) into which was inserted a beveled 32 gauge fused silica tube (Polymicro Technologies, Phoenix, AZ). Hemicellulose dialysis tubing [molecular weight of $12 \mathrm{kDa}$ cutoff; $230 \mu \mathrm{m}$ outer diameter; Spectra-por (Fisher Scientific, Pittsburgh, PA)] was inserted $\sim 1.0 \mathrm{~mm}$ into the outer cannula and secured with epoxy glue. The distal end of the membrane was cut to a length of $1.5 \mathrm{~mm}$, and the tip was sealed with epoxy, providing an active dialyzing length of $1.0 \mathrm{~mm}$. Microdialysis was performed by continuously perfusing probes with filtered artificial CSF (ACSF) composed of the following (in $\mathrm{mm}$ ): $147 \mathrm{NaCl}, 4.0 \mathrm{KCl}, 1.8$ $\mathrm{CaCl}_{2}, \mathrm{pH} 7.5$, at a flow rate of $1.2 \mu \mathrm{l} / \mathrm{min}$ using a calibrated syringe pump (CMA/100; Bioanalytical Systems, West Lafayette, IN) attached to an overhead liquid swivel (Instech, Plymouth Meeting, PA). The assembly allowed the animals freedom of movement within the cage throughout the duration of the experiment. For all experiments, measurement of extracellular 5-HT in the SCN was aided by adding $4.0 \mu \mathrm{M}$ citalopram to the perfusate. The sampling interval was $20 \mathrm{~min}$.

Microdialysate was analyzed for 5-HT using HPLC (Bioanalytical Systems) with amperometric electrochemical detection. Samples were injected onto a $100 \times 1 \mathrm{~mm} 3 \mu \mathrm{C}$ - 18 reverse-phase microbore column. The mobile phase consisted of $9.45 \mathrm{gm}$ of monochloroacetic acid (Fisher Scientific), $0.2 \mathrm{gm}$ of octanesulfonic acid, and $0.25 \mathrm{gm}$ of $\mathrm{Na}_{2}$ EDTA (Eastman Kodak, Rochester, NY) dissolved in 1.0 1 HPLC-grade distilled water, $\mathrm{pH}$ 3.1. Tetrahydrofuran $(6.0 \mathrm{ml})$ was added after filtration. Flow rate of the mobile phase through the column was $90 \mu \mathrm{l} / \mathrm{min}$. A $3.0 \mathrm{~mm}$ glassy carbon radial-flow electrochemical detector set at a potential of $590 \mathrm{mV}$ relative to an $\mathrm{AgCl}$ reference electrode was used to measure 5 -HT. The lower level of sensitivity (signal $\geq 5 \times$ background) was $\sim 500$ fg. Electrode output was interfaced with an IBM-compatible computer that recorded and analyzed the data. Authenticity of the 5-HT peak in SCN microdialysate was verified by predictable changes in its size after electrical and pharmacological stimulations of the raphe and localized administration of pharmacological agents to the SCN via the dialysis probe (Dudley et al., 1998).

\section{Circadian wheel-running activity measurements}

Daily wheel-running activity was recorded by a magnetic switch attached to a running wheel (14 inch diameter, $1.5 \mathrm{~kg}$; zcomNalge Nunc International, Rochester, NY) with its output interfaced with a computerized data acquisition system (Dataquest, Sunriver, OR). Circadian phase resetting was assessed using a modified Aschoff type II procedure (Aschoff, 1965), in which animals maintained under LD up to the time of experimentation were released into total darkness (DD) at the beginning of the experimental treatments initiated at zeitgeber time (ZT) 6. Phase shifts of the circadian wheel-running rhythm were calculated as the difference between the averaged activity onset for $5 \mathrm{~d}$ preceding drug treatment and onsets predicted by least squares regression analysis of activity onsets from days 3-10 after treatment. Activity onset was defined as the first 10 min period in which the total number of wheel revolutions (revs) exceeded $50 \%$ of the maximum number of revolutions per 10 min measured that day and was followed by at least $1 \mathrm{hr}$ of sustained activity.

\section{Experimental protocols}

Effects of 5-HT antagonists on DRN-electrically stimulated SCN 5-HT release. A 20 min period of DRN electrical stimulation was begun in the middle of the light phase at ZT 6 (ZT 12 was time of lights off). Microinjections of drugs [the 5 - $\mathrm{HT}_{1,2,7}$ antagonist metergoline $(2 \mu \mathrm{g}, 1 \mu \mathrm{l}$ volume; Sigma, St. Louis MO); the selective $5-\mathrm{HT}_{7}$ antagonist DR4004 (Kikuchi et al., 1999) (2 $\mu \mathrm{g}, 1 \mu \mathrm{l}$ volume; Meiji Seika Kaisha, Yokohama, Japan)] or vehicle (1:1 ACSF/DMSO, $1 \mu$ lvolume) were administered via an injection cannula aimed at the DRN or MRN 20 min before the onset of the DRN stimulation. For SCN measurements, the microdialysis probe was perfused for a $2 \mathrm{hr}$ equilibration period beginning at ZT 3, followed by a $1 \mathrm{hr}$ sample collection period to establish baseline 5 -HT release levels. Microdialysis sampling was continued for $2 \mathrm{hr}$ after the antagonist injection. Trials were conducted over 3 consecutive days on the same animal, with drugs or injection vehicle administered randomly. Control experiments assessing the effects of intra-raphe administration of metergoline, DR4004, or vehicle alone (without electrical stimulation) on SCN 5-HT release were also undertaken.

Effects of intra-DRN 5-HT antagonists on sleep deprivation-induced SCN 5-HT release. The procedures used for sleep deprivation were similar to those used in a previous study (Grossman et al., 2000). Beginning at ZT 6, animals outfitted with a microdialysis probe in the SCN and an injection reentry cannula aimed at the DRN were aroused and maintained in the waking state in their home cage for $3 \mathrm{hr}$ by continuous gentle handling and light puffs of air. After the $3 \mathrm{hr}$ experimental period, the animals were left undisturbed. These procedures were performed under dim red light ( $<1.0$ lux) because bright light inhibits nonphotic phase resetting (Antle and Mistlberger, 2000). Microdialysis sampling was undertaken continuously from ZT 5 to 10 with a 20 min sampling 
interval. An initial intra-DRN metergoline [(experimental) $2 \mu \mathrm{g}, 1 \mu \mathrm{l}$ volume)] or vehicle [(control) 1:1 DMSO/ACSF, $1 \mu$ l volume] microinjection was administered $20 \mathrm{~min}$ before the onset of the sleep deprivation, and a second microinjection of the same respective solution was delivered $2 \mathrm{hr}$ later. The experiment was undertaken using a paired design in which the animals received both experimental and control treatments in random order over 2 consecutive days.

Intra-DRN and intra-MRN GABAergic effects on SCN 5-HT release. Microinjections of the $\mathrm{GABA}_{\mathrm{A}}$ antagonist bicuculline (125 ng, $500 \mathrm{nl}$ volume) or the $\mathrm{GABA}_{\mathrm{A}}$ agonist muscimol ( $25 \mathrm{ng}, 500 \mathrm{nl}$ volume; Sigma) were administered to the DRN and the MRN to explore the role of raphe GABAergic mechanisms in regulating SCN 5-HT release. All drugs were administered by microinjection aimed at the DRN or MRN at ZT 6 . Microdialysis measurements of SCN 5-HT release were undertaken as described above. Sampling was undertaken continuously for $3 \mathrm{hr}(1 \mathrm{hr}$ before and $2 \mathrm{hr}$ after drug injection).

Intra-DRN 5-HT $T_{7}$ and $G A B A_{A}$ antagonist effects on SCN 5-HT release. Coapplications of bicuculline and DR4004 in the DRN were undertaken to determine whether stimulation of SCN 5-HT release elicited by $\mathrm{GABA}_{\mathrm{A}}$ receptor antagonism is prevented by $5-\mathrm{HT}_{7}$ receptor blockade in the same manner as DRN-electrically stimulated SCN 5-HT release is blocked with 5-HT antagonists. Animals received microinjection of DR4004 ( $2 \mu \mathrm{g}, 1 \mu \mathrm{l}$ volume) $20 \mathrm{~min}$ before microinjection of bicuculline (125 ng, $500 \mathrm{nl}$ volume) delivered from the same cannula at ZT 6. Microdialysis measurements of SCN 5-HT release were undertaken continuously for $3 \mathrm{hr}$ ( $1 \mathrm{hr}$ before and $2 \mathrm{hr}$ after bicuculline injection).

Intra-DRN 5-HT $T_{7}$ antagonist and $G A B A_{A}$ agonist effects on novel wheelinduced phase resetting. Intra-DRN injections of DR4004 and muscimol were undertaken to determine whether the pharmacological interventions that suppressed SCN 5-HT release could also inhibit behavioral phase resetting. Novel wheel access was used rather than sleep deprivation in these trials because the former stimulus, due to the inter-animal variation in wheel-running performance, offers the advantage of testing drug effects over a broader range of phase-resetting response. A possible potentiating effect of bicuculline on phase resetting was not evaluated because of the acute arousal reaction induced by intra-DRN injection of this drug. The circadian wheel-running activity rhythm of hamsters outfitted with a unilateral reentry injection cannula aimed at the DRN was measured for a minimum of $10 \mathrm{~d}$ under LD preceding experimentation. On the day of treatment, the animals received an injection of DR4004, muscimol (same doses as those used in the 5-HT release experiments), or vehicle and were removed from their home cage and confined in a novel wheel for a $3 \mathrm{hr}$ period beginning at ZT 6 . A second injection of respective drug or vehicle was administered at ZT 7.5, and the animals were returned to their home cage at ZT 9. The animals were released into DD at the beginning of the novel wheel confinement, and their phase-resetting response was determined using the modified Aschoff II procedure described above. The number of revolutions induced by the novel wheel exposure was recorded over the $3 \mathrm{hr}$ experimental period and after return to the home cage and wheel.

\section{Histological evaluations of intracranial implant sites}

After completion of the experiments, the locations of the implants were verified histologically. Hamsters were deeply anesthetized with Nembutal and perfused intracardially with $100 \mathrm{ml}$ of buffered $4 \%$ paraformaldehyde. The brains were removed and postfixed in $4 \%$ paraformaldehyde overnight. Cryostat sections of the SCN region $(20 \mu \mathrm{m})$ were stained with cresyl violet for light microscopic verification of microdialysis probe placement. A separate tissue block containing the midbrain was serially sectioned $(60 \mu \mathrm{m})$ on a vibratome and processed immunocytochemically for 5-HT to verify electrode or cannula tip location among 5-HT neurons of the MRN or DRN. Staining for 5-HT was undertaken using a rabbit polyclonal anti-5-HT (Eugenetech, Farmendale, NJ).

\section{Brain implant specificity considerations}

Electrical stimulations. Nonspecific excitation by passive current spread from the DRN to the MRN was evaluated previously using electrodes aimed $\sim 0.8 \mathrm{~mm}$ dorsolateral to the MRN (Dudley et al., 1999). Stimulation from these electrodes did not affect SCN 5-HT release; therefore, it is unlikely that passive current flow from electrodes in the DRN would affect MRN neurons located farther away ( $\sim 2.0 \mathrm{~mm}$ ventral) from the stimulation site.

Drug stimulations. Diffusion of drugs between the DRN and MRN was evaluated by comparing responses of the different nuclei with the same doses of drugs. The differential effects obtained [i.e., threefold greater response to 8-OH-DPAT or WAY 100635 injections into the MRN versus the DRN (Dudley et al., 1999)] indicate that the effects of the drugs were registered primarily at the site of injection. Also, the lack of effect of DRN injections that were off target by $\sim 1 \mathrm{~mm}$ supports this contention.

5-HT microdialysis measurements. Site specificity of the SCN microdialysis measurements has been empirically evaluated (Dudley et al., 1999). Probes with a small window of active dialysis membrane were aimed medially at the SCN to limit sample contamination from 5-HT of extra-SCN origin. This method provided equivalent estimations of peak DRN-stimulated 5-HT release as obtained using the conventional concentric probes, confirming that most of the of 5-HT measured by these probes is from SCN origin.

\section{Statistics}

The SCN 5-HT release data were normalized as a percentage of the pretreatment baseline level. Pretreatment versus post-treatment comparisons were undertaken using one-way repeated measures ANOVA followed by the Student-Newman-Keuls test. Treatment versus control comparisons for a given time point were analyzed using a paired $t$ test. A two-way ANOVA was also undertaken to compare treatment and site effects over time. Drug effects on wheel-running-induced phase resetting were analyzed using a one-way ANOVA followed by the Student-Newman-Keuls test. For all procedures, the level of significance was set at $p<0.05$.

\section{Results}

\section{Intra-raphe 5-HT antagonist injection inhibits 5-HT release in the $\mathrm{SCN}$}

\section{DRN 5-HT antagonist treatments}

Pretreatment with an intra-DRN injection of metergoline abolished the DRN-electrically stimulated release of 5-HT in the SCN [peak levels within $40 \mathrm{~min}$ after stimulation were $176 \pm 17$ vs $96 \pm 10 \%$ of baseline for vehicle and metergoline treatments, respectively $(n=6$ per group; $p<0.01$ ) (Fig. $1 A$ )]. A two-way ANOVA revealed that drug treatment, time, and their interaction were all significant $(p<0.01)$. In a similar manner, pretreatment of DRN-electrically stimulated animals with intra-DRN injection of the highly selective $5-\mathrm{HT}_{7}$ antagonist DR4004 blocked the stimulation of 5-HT release in the SCN [peak levels within $40 \mathrm{~min}$ after stimulation were $196 \pm 26$ vs $100 \pm 9 \%$ of baseline for vehicle and DR4004 treatments, respectively $(n=5$ per group; $p<0.01$ ) (Fig. 1B)]. Drug treatment, time, and their interaction were all significant $(p<0.01)$. Intra-DRN injections of metergoline or DR4004 alone (without electrical stimulation) reduced basal release of 5-HT in the SCN during an equivalent sampling period by $\sim 25 \%$ versus vehicle $(n=4$ per group; $p<0.05$ for both drugs) (Fig. 1C).

\section{MRN 5-HT antagonist treatments}

Pretreatment of DRN-electrically stimulated animals with intraMRN injection of metergoline or DR4004 had similar effects as those described for intra-DRN antagonist applications. DRNelectrically stimulated release of 5-HT in the SCN was prevented by metergoline [peak levels within $40 \mathrm{~min}$ after stimulation were $187 \pm 17$ vs $104 \pm 15 \%$ of baseline for vehicle and metergoline treatments, respectively $(n=6$ per group; $p<0.01)$ (Fig. $2 A)]$. Drug treatment, time, and their interaction were all significant $(p<0.01)$. Similar to metergoline, DRN-stimulated SCN 5-HT release was blocked by DR4004 [peak levels within 40 min after stimulation were $168 \pm 20$ vs $95.5 \pm 6 \%$ of baseline for vehicle and DR4004 treatments, respectively $(n=4$ per group; $p<0.05)$ 


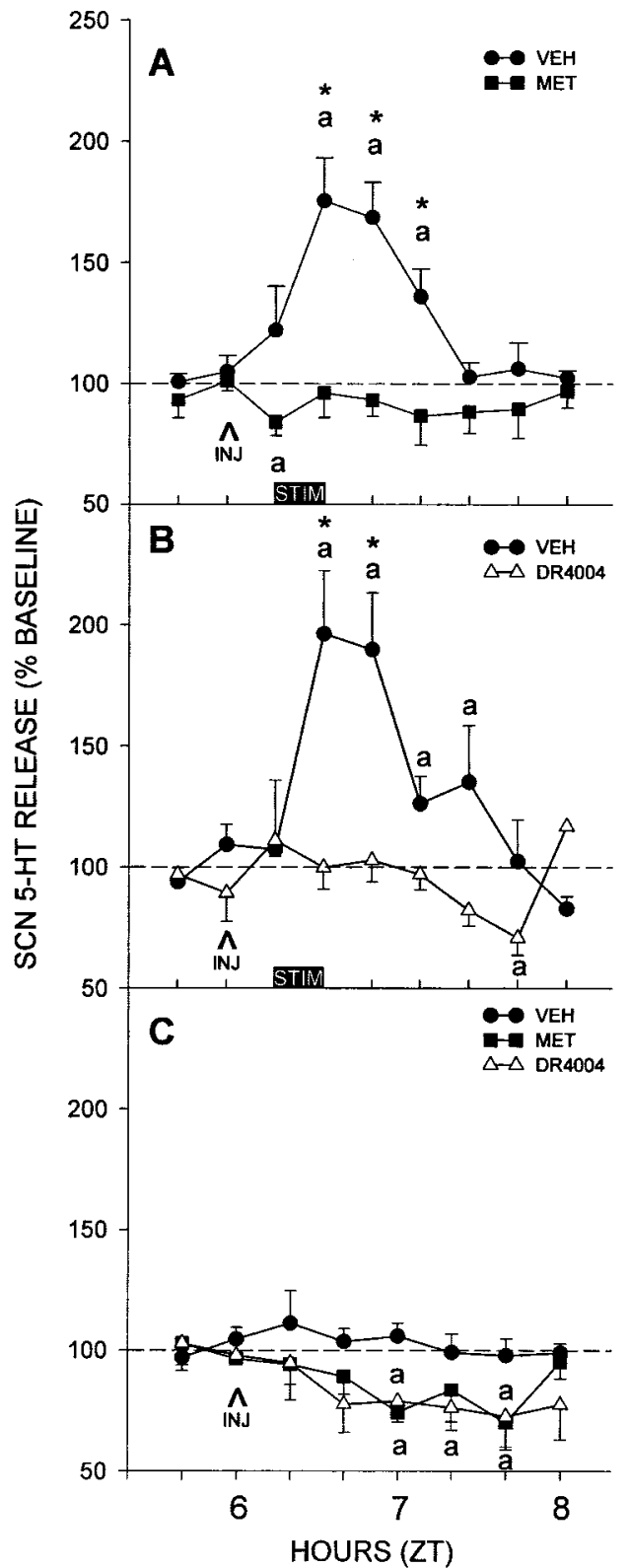

Figure 1. Suppressive effects of intra-DRN microinjection of 5-HT antagonists on SCN 5-HT release evoked by electrical DRN stimulation. $A$, Metergoline (MET; $n=6) . B, \mathrm{DR} 4004(n=5)$. Both drug treatments abolished the stimulated 5 -HT release seen in vehicle (VEH) controls ( $n=$ $6, n=5$, respectively). These antagonists also suppressed basal SCN 5-HT output by $\sim 25 \%$ when injected into the DRN alone without electrical stimulation $\left(C ; n=4\right.$ per group). ${ }^{\mathrm{a}} p<0.05$ versus pretreatment baseline levels; ${ }^{*} p<0.05$ versus vehicle controls for a given time point. The 20 min period of electrical stimulation is represented by the horizontal bars designated STIM; INJ, drug or vehicle injection. Data are mean \pm SEM.

(Fig. $2 B)$ ]. Drug treatment, time, and their interaction were all significant $(p<0.01)$.

\section{Intra-DRN metergoline blocks behaviorally induced 5-HT} release in the SCN

Like previous reports from this laboratory (Grossman et al., 2000), $3 \mathrm{hr}$ of sleep deprivation under dim red light during the subjective midday induced a prolonged increase in 5 -HT release in the SCN with maximal levels $[151 \pm 10 \%$ of pretreatment baseline $(n=5) ; p<0.05$ ] occurring within $2 \mathrm{hr}$ from the onset of treatment (Fig. 3). The average increase in 5-HT release

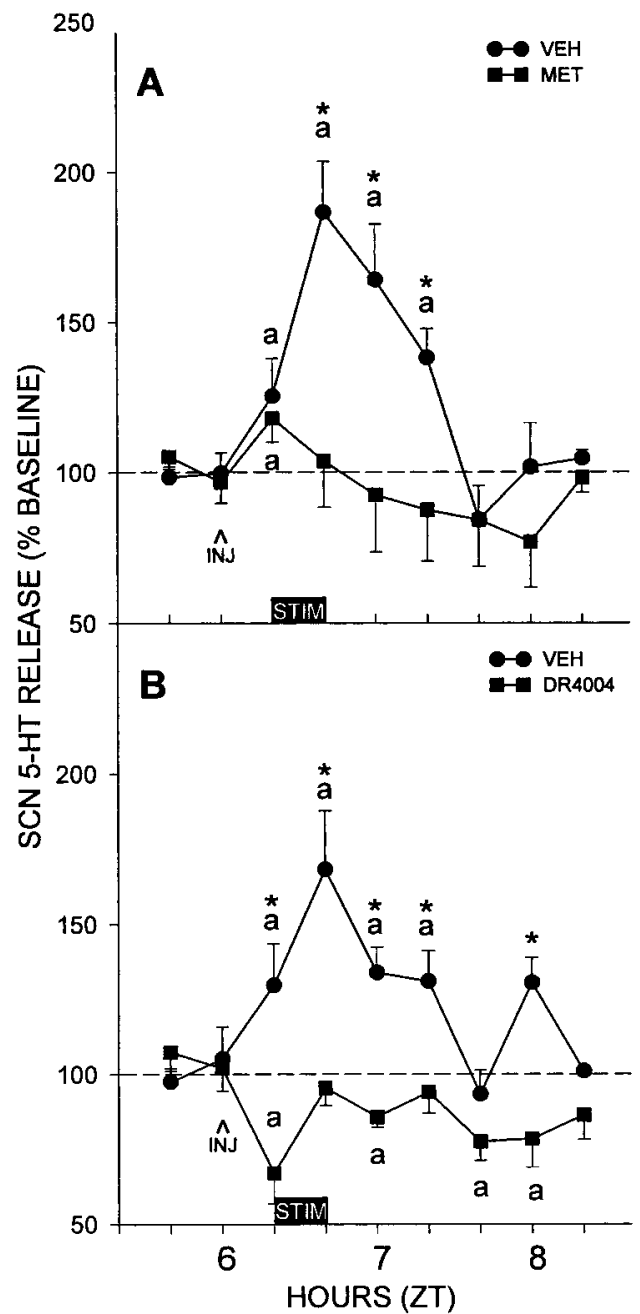

Figure 2. The suppressive effects of intra-MRN microinjection of 5-HT antagonists on SCN 5 -HT release evoked by electrical DRN stimulation. $A$, Metergoline (MET; $n=6$ ). B, DR4004 $(n=4)$. Similar to DRN injections, both drugs injected into the MRN abolished DRN-stimulated 5 -HT release. ${ }^{a} p<0.05$ versus pretreatment baseline levels; ${ }^{*} p<0.05$ versus vehicle (VEH) controls for a given time point. The 20 min period of electrical stimulation is represented by the horizontal bars designated STIM; INJ, drug or vehicle injection. Data are mean \pm SEM.

throughout the entire $3 \mathrm{hr}$ treatment period was $134 \pm 3 \%$ ( $p<$ 0.05 vs baseline). In marked contrast, the stimulatory effect of sleep deprivation on SCN 5-HT release was abolished in animals treated with an intra-DRN injection of the $5-\mathrm{HT}_{1,2,7}$ antagonist metergoline (Fig. 3). The average change in 5-HT release throughout this treatment period was $-17 \pm 9 \%[p>0.37$ vs pretreatment baseline $(n=5) ; p<0.05$ vs vehicle controls]. Two-way ANOVA revealed a significant difference between metergoline and vehicle treatment $(p<0.01)$.

\section{Raphe GABA receptors modulate 5-HT release in the SCN} Bicuculline stimulates SCN 5-HT release

Microinjection of the $\mathrm{GABA}_{\mathrm{A}}$ receptor antagonist bicuculline into the DRN dramatically stimulated 5-HT release in the SCN, with maximal levels ( $264 \pm 64 \%$ of baseline; $p<0.05 ; n=5$ ) sustained over a $40 \mathrm{~min}$ period after injection (Fig. $4 A$ ). The stimulated increase of 5-HT release was approximately twice that observed in response to electrical stimulation or sleep deprivation (Fig. 4A). Injection of bicuculline into the MRN also had a stimulatory effect on SCN 5-HT release, but this was less than induced by the DRN treatment, with maximal levels (174 $\pm 16 \%$ 


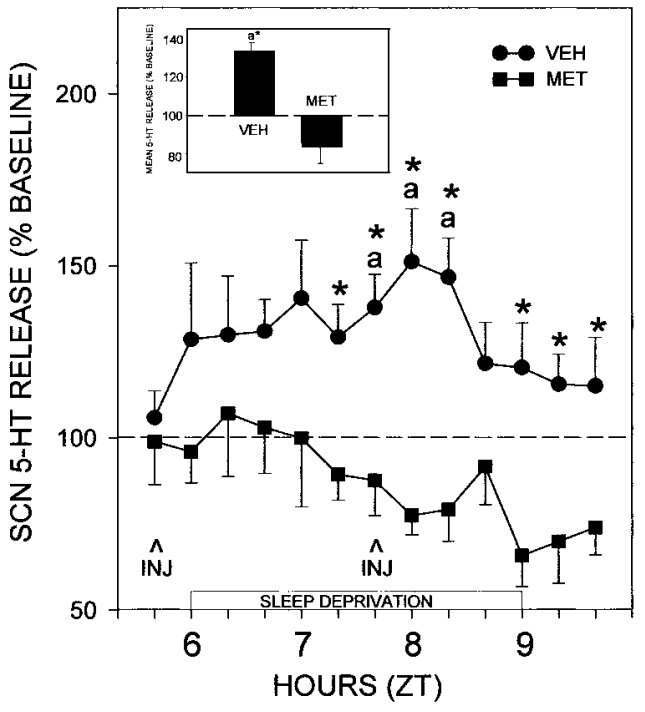

Figure 3. Blocking effect of intra-DRN microinjection of metergoline (MET) on sleep deprivation-induced 5-HT release in the $\mathrm{SCN}$. Consistent with our previous published results, sleep deprivation caused $\sim 150 \%$ increase in SCN 5 -HT release. This was completely blocked by the metergoline treatment. Inset, Integrated values for 5 -HT release as a percentage of pretreatment baseline over the $3 \mathrm{hr}$ sleep deprivation period designated by the horizontal bar. For both graphs, ${ }^{a} p<0.05$ versus pretreatment baseline levels; ${ }^{*} p<0.05$ versus vehicle (VEH) controls for a given time point. Data are mean $\pm \operatorname{SEM}(n=5$ per group).

of baseline; $p<0.05 ; n=5$ ) occurring within 40 min after injection (Fig. 4A). Two-way ANOVA revealed significance between DRN and MRN groups, time, and the interaction between time and groups $(p<0.01)$.

\section{Muscimol inhibits SCN 5-HT release}

Microinjection of the $\mathrm{GABA}_{\mathrm{A}}$ receptor agonist, muscimol, into the DRN reduced 5-HT release in the SCN to $72 \pm 8 \%$ of baseline levels within 20 min after injection $(p<0.05 ; n=6)$ (Fig. $4 B$ ). Microinjection of muscimol to the MRN also reduced SCN 5-HT release $(73 \pm 7 \%$ of baseline; $n=5 ; p<0.05$ ) (Fig. $4 B$ ). A two-way ANOVA revealed differences between DRN and MRN groups $(p<0.01)$, time $(p<0.01)$, and the interaction between time and groups $(p<0.05)$. However, as evident in the bicuculline response, the latency of muscimol action in the MRN was greater than that observed for the DRN, with maximal suppression occurring $60 \mathrm{~min}$ after injection.

\section{Intra-DRN DR4004 inhibits bicuculline-stimulated SCN}

5-HT release

Pretreatment with intra-DRN microinjection of DR4004 blocked the stimulatory effect of intra-DRN microinjection of bicuculline on SCN 5-HT release (Fig. 4C). Two-way ANOVA revealed differences between bicuculline and DR4004 plus bicuculline treatments and time $(p<0.01)$. The similarity in action between the blocking effects of intra-DRN 5-HT antagonists on GABA antagonist and electrical and behavioral stimulations of SCN 5-HT output indicates the involvement of GABA in the same pathway(s) mediating both the exogenous and endogenous DRNmediated activation of 5-HT release in the SCN.

Electrical DRN stimulation induces 5-HT release in the MRN A direct functional serotonergic communication between the DRN and MRN is indicated by our finding that stimulation of the DRN elicits 5-HT release in the MRN. The 20 min pulse of DRN electrical stimulation increased extracellular 5-HT release in the

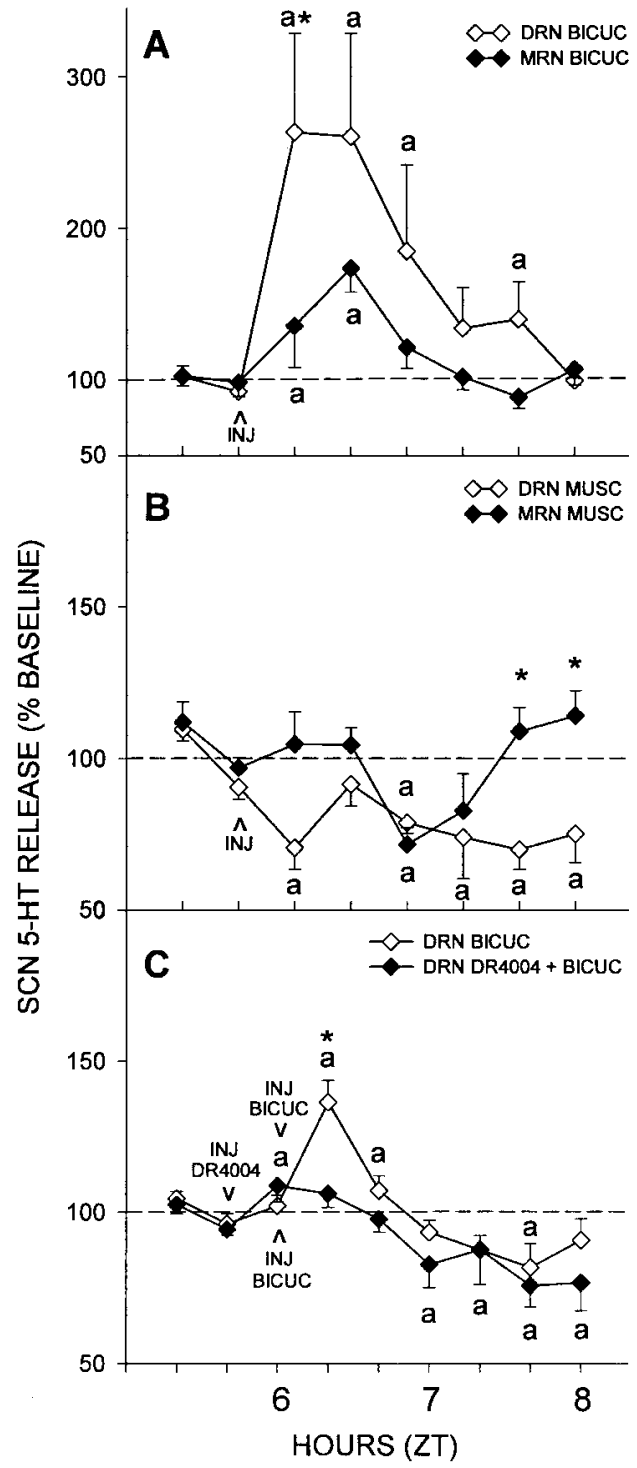

Figure 4. Effects of intra-raphe microinjection of $\mathrm{GABA}_{A}$ receptor ligands on $\mathrm{SCN}$ 5-HT release. $A$, Injection of the $G A B A_{A}$ agonist bicuculline (BICUC) into the DRN $(n=5)$ and MRN ( $n=$ 5) significantly stimulated 5 -HT release. $B$, Injection of the $G_{A B A_{A}}$ antagonist muscimol (MUSC) into the DRN $(n=6)$ and MRN $(n=5)$ suppressed 5-HT release, with the duration of this effect being greater in the DRN. C, The stimulatory effect of intra-DRN injection of bicuculline is abolished by intra-DRN pretreatment with DR4004 ( $n=5$ per group). For all graphs, ${ }^{a} p<0.05$ versus pretreatment baseline levels; $p<0.05$ versus complementary site-drug treatment for a given time point. Data are mean $\pm S E M$. Differences in bicuculline potency between the two experiments were caused primarily by the greater variability in response in $A$ and possibly differences in drug potency between different lots that were used.

MRN by $142 \pm 21 \%$ of nonstimulated control levels $(p<0.05$; $n=6$ ) (Fig. 5).

The DRN modulates behavioral circadian phase resetting Similar to other studies in the Syrian hamster (Bobrzynska and Mrosovsky, 1998; Meyer-Bernstein and Morin, 1998), there was a wide range of response to novel wheel access, with the majority of animals of the vehicle control and drug treatment groups running $<400$ revolutions over the $3 \mathrm{hr}$ treatment period (Fig. 6). Control animals exceeding the 400-500 revolution level exhibited peak phase-advancing responses averaging $136 \pm 23 \mathrm{~min}$ $(n=4)$, whereas most individuals running below this level responded with considerably smaller responses averaging $44 \pm 10$ 


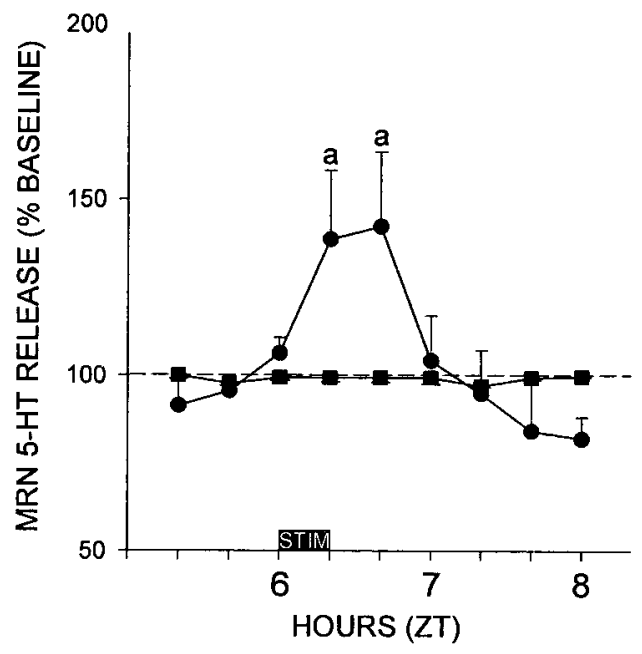

Figure 5. Electrical stimulation of the DRN induces 5-HT release in the MRN. Solid circles, Electrical stimulation; solid squares, nonstimulated controls. a is significantly different from controls for a given time point; $p<0.05$.

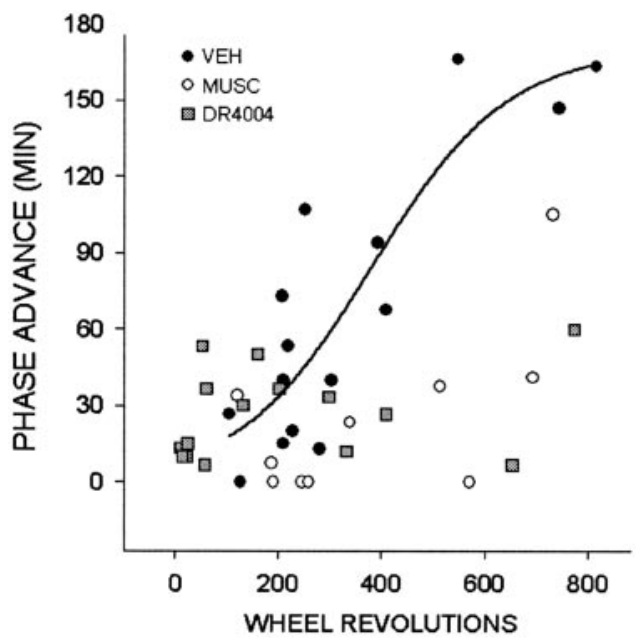

Figure 6. Relationship between the number of wheel revolutions during the $3 \mathrm{hr}$ novel wheel exposure and induced phase-advance shifts in animals that received intra-DRN injection of vehicle (VEH), muscimol (MUSC), or DR4004. For reference, a line was plotted for the control data only, using a sigmoidal 3 parameter equation (Sigma Plot, Jandel Scientific, Corte Madera, CA).

$\min (n=11 ; p<0.05)$. Thus, under control conditions, the $400-500$ revolution range was considered to be an index for attaining maximal phase-advancing response. Animals receiving intra-DRN muscimol that ran at or above this range had phase advances that were significantly smaller than controls running in this range ( $46 \pm 22 \mathrm{~min} ; n=4 ; p<0.05$ vs controls) (Fig. 7). Muscimol-treated animals running below this range $(n=6)$ also had phase advances that were less than those of controls running in a similar range (11 \pm 6 min; $n=6$; $p<0.05$ vs controls). Animals receiving intra-DRN DR4004 that ran above this range had phase advances that were smaller than controls $(31 \pm 15 \mathrm{~min}$; $n=3 ; p<0.05$ vs controls) (Fig. 7). DR4004-treated animals running less than this range had phase advances similar to both the control and muscimol groups ( $26 \pm 5 \min ; n=12$; both $p>$ $0.05)$. Actograms representing the three treatment groups are presented in Figure 8.

Despite the individual variability in wheel-running response, the overall average revolutions for every animal in each treatment

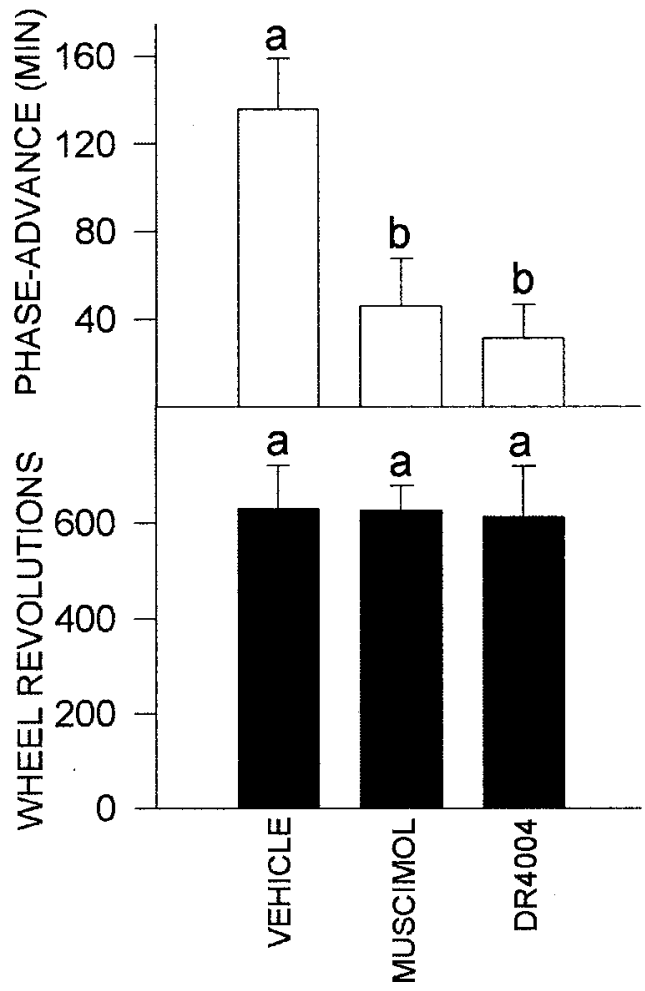

Figure 7. Effects of intra-DRN muscimol and DR4004 injection on novel wheel-induced phase resetting. Top, Phase-advance shifts for animals that ran at or exceeded the 400-500 revolution index range for maximal shifting response. Bottom, Number of wheel revolutions for groups of animals represented in the top. Vehicle, $n=4$; muscimol, $n=4 ;$ DR4004, $n=3$. For each graph, bars with different letters are significantly different. Data are mean \pm SEM.

group during the $3 \mathrm{hr}$ treatment period did not differ significantly (control, $337 \pm 55$ revs; muscimol, $386 \pm 71$ revs; DR4004, $214 \pm$ 62 revs; both drug groups $p>0.15$ vs control). However, overall analysis of phase shifting for every animal in each group revealed significant drug-related differences in response (control, $68 \pm 14$ min; muscimol, $25 \pm 10 \mathrm{~min}$; DR4004, $27 \pm 5 \mathrm{~min}$; both drug groups, $p<0.05$ vs control). Also, for animals running at or above the 400-500 revolution range, the mean level of running for controls also was not statistically significant from the drug groups (control, $630 \pm 93$; muscimol, $628 \pm 51$; DR4004, $612 \pm$ 106; $p<0.98$ ) (Fig. 7). Therefore, the reduced phase-resetting response of animals treated with muscimol or DR4004 that performed at or above this range is not attributable to a drug-related suppression of wheel running.

\section{Discussion}

Serotonergic input to the $\mathrm{SCN}$ from the midbrain raphe nuclei is important for maintaining normal circadian rhythmicity; however, the respective roles of the DRN and MRN in regulating this input remain uncertain. The MRN is the only direct source of serotonergic innervation to the SCN in the Syrian hamster (Meyer-Bernstein et al., 1997), but stimulation of either raphe nucleus in this species elicits multiple 5-HT-related effects in the SCN (Meyer-Bernstein and Morin, 1996, 1997; Yu et al., 1997; Weber et al., 1998), including 5-HT release (Dudley et al., 1999). We therefore proposed a multisynaptic $\mathrm{DRN} \rightarrow \mathrm{MRN} \rightarrow \mathrm{SCN}$ pathway to match these findings with the raphe-SCN mapping data. This pathway is supported by observations that DRNelectrically stimulated $5-\mathrm{HT}$ release in the $\mathrm{SCN}$ is blocked by 


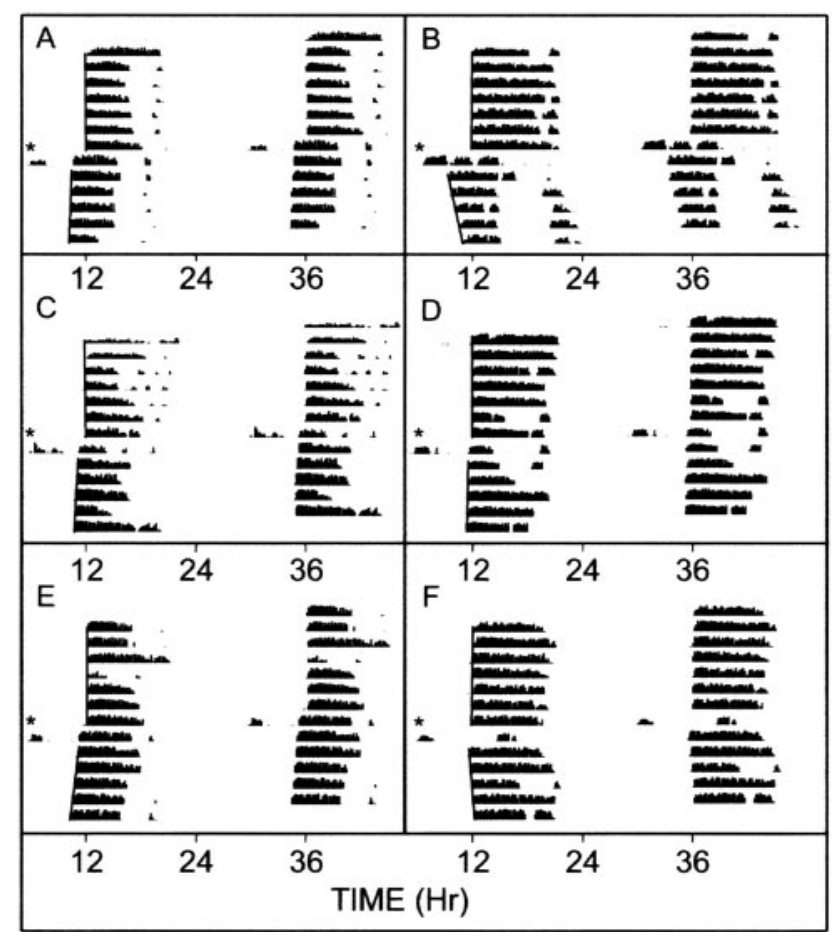

Figure 8. Double-plotted wheel-running activity records showing representative profiles from the three treatment groups. Days are indicated vertically from top to bottom, and time is indicated horizontally. Asterisks represent the onset of the novel wheel exposure at ZT 6 and release into constant darkness for the Aschoff type II protocol. Activity on the novel wheel was recorded by switching the output signal of the wheel into the home cage monitor channel. After $3 \mathrm{hr}$, the animal was returned to the home cage (with wheel unlocked). See Materials and Methods for details of the behavioral phase-shifting measurements. $A, B$, Intra-DRN vehicle control.C, D, Intra-DRN muscimol. $E, F$, Intra-DRN DR4004. The bottom axis represents external time.

systemic treatment with the $5-\mathrm{HT}_{1,2,7}$ antagonist metergoline, indicative of a multisynaptic, 5-HT-sensitive route from the DRN to the SCN (Dudley et al., 1999; Glass et al., 2000). The present results reveal also that the 5-HT-sensitive components of this pathway are associated with the raphe nuclei themselves because DRN-electrically stimulated SCN 5-HT release is blocked by intra-DRN and intra-MRN injections of 5-HT antagonists and DRN stimulation induces 5-HT release in the MRN. The physiological significance of these observations is underscored by the demonstration that the acute increase in SCN 5-HT release induced by sleep deprivation is similarly blocked by intra-DRN treatment with metergoline. Importantly, a modulatory role of the DRN in nonphotic phase resetting is indicated by the finding that intra-DRN injections of DR4004 or the GABA A agonist muscimol (both of which suppress SCN 5-HT release) attenuate, but do not block, circadian phase-advance shifts induced by novel wheel access.

It is notable that intra-DRN 5-HT antagonist application blocks the effects of electrical stimulation of DRN cells, suggesting that the 5-HT antagonists block postsynaptic targets of the stimulated DRN cells. The marked similarities between the inhibitory effects of intra-DRN 5-HT antagonists on behavioral, bicuculline, and electrically stimulated SCN 5-HT release indicate that the electrical stimulation activates the same population of DRN neurons as do these other modes of stimulation.
Raphe 5- $\mathrm{HT}_{7}$ receptors regulate behavioral 5-HT release in the SCN

The present observations that DRN-electrically stimulated SCN 5-HT release and novel wheel-induced phase shifts are attenuated by intra-DRN application of metergoline and/or DR4004, both of which antagonize the $5-\mathrm{HT}_{7}$ receptor, implicate DRN 5- $\mathrm{HT}_{7}$ receptors in the regulation of circadian timekeeping. The 5- $\mathrm{HT}_{7}$ receptor has been localized immunocytochemically in fibers and cell bodies in various circadian-related brain sites, including the DRN and SCN (Pickard and Belenky, 2000; Duncan et al., 2001), and is thought to mediate the circadian phase-resetting effect of 5-HT in the SCN (Lovenberg et al., 1993; Ehlen et al., 2001). $5-\mathrm{HT}_{7}$ receptor binding has been identified autoradiographically in the DRN, MRN, IGL, and SCN of hamsters, and significantly, only $5-\mathrm{HT}_{7}$ receptor binding in the DRN changes with aging and in accordance with age-related 8-OH-DPAT phase-resetting effects (Duncan et al., 1999). This points to a unique role of DRN $5-\mathrm{HT}_{7}$ receptors in regulating serotonergic circadian clockresetting responses, which has direct relevance to the present data linking these DRN receptors to circadian phase-regulating mechanisms.

\section{Serotonergic regulation of circadian phase}

An important issue related to the present assessment of raphe function is that of a direct phase-regulating action of 5-HT in the SCN (for review, see Morin, 1999; Mistlberger et al., 2000). The intrinsic pattern of activity of 5-HT neurons varies in accordance with behavioral state (Trulson and Jacobs, 1983; Jacobs and Fornal, 1997), and 5-HT release induced in the SCN by behavioral phase-resetting stimuli (Dudley et al., 1998; Grossman et al., 2000) could serve as an intrinsic clock-resetting feedback signal. Although a role for 5-HT is not certain (Bobrzynska et al., 1996; Mintz et al., 1997; Meyer-Bernstein and Morin, 1998), evidence supporting a phase-resetting action of 5-HT in the SCN includes reports that in vitro application of 5-HT receptor agonists to the SCN brain slice preparation during subjective midday advances the circadian rhythm of neuronal activity (Prosser et al., 1990, 1993; Medanic and Gillette, 1992; Shibata et al., 1992). Also, in vivo administration of 8-OH-DPAT into the third ventricle upstream from the SCN in rats (Edgar et al., 1993) or bilateral microinjections of 8-OH-DPAT into the SCN region of hamsters (Challet et al., 1998) phase advances the circadian clock, and depletion of 5-HT in the SCN by neurotoxic lesioning prevents entrainment to daily schedules of activity in mice (Edgar et al., 1997; Marchant et al., 1997). More recently, perfusions of the SCN with 8-OH-DPAT or 5-HT using reverse microdialysis in hamsters were shown to phase advance the clock at midday in a tetrodotoxin-insensitive manner, suggesting a direct in vivo phase-resetting action of 5-HT on clock cells (Ehlen et al., 2001).

\section{Intra-raphe GABAergic mechanisms regulate SCN 5- HT release}

The respective stimulatory and inhibitory effects of intra-raphe injection of the $\mathrm{GABA}_{\mathrm{A}}$ antagonist bicuculline and the $\mathrm{GABA}_{\mathrm{A}}$ agonist muscimol on SCN 5-HT release support a role of GABA in the regulation of midbrain raphe activity. These results are consistent with reports that GABA inhibits DRN neuronal activity (Gallager and Aghajanian, 1976; Levine and Jacobs, 1992) and mediates IPSPs in DRN serotonergic cells (Pan and Williams, 1989). Also, reduced DRN neuronal discharge during sleep is 


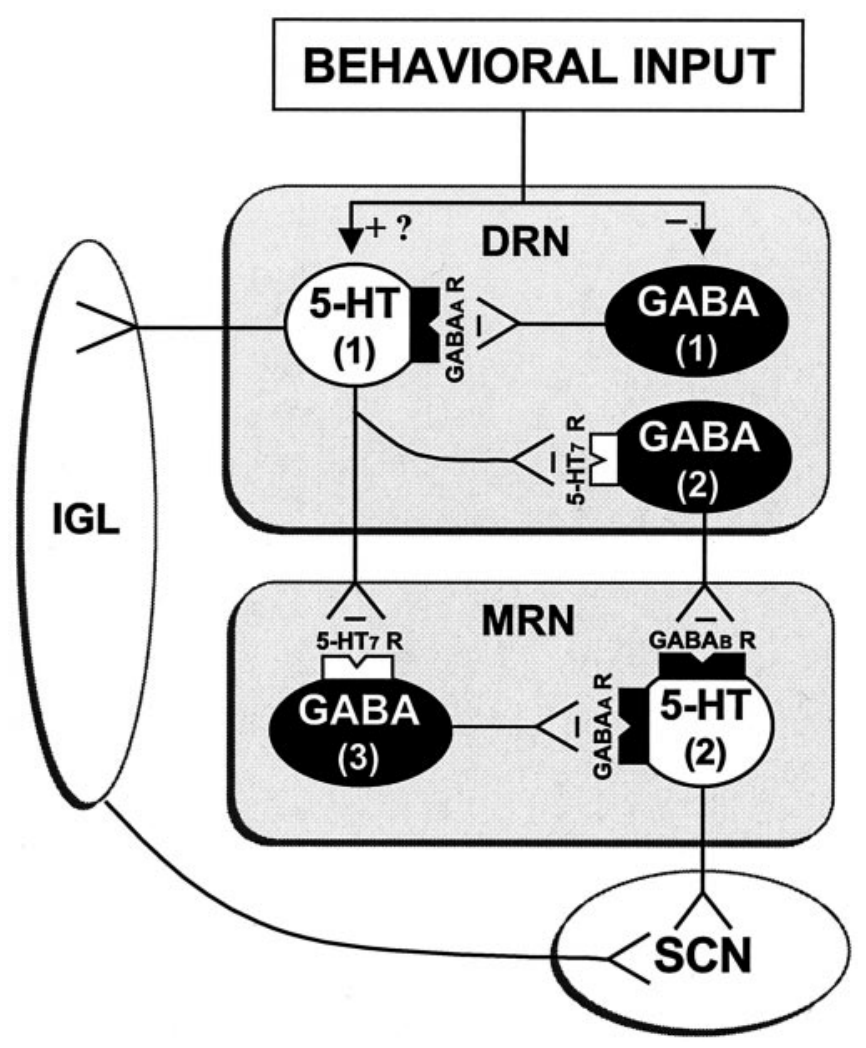

Figure 9. The proposed mechanism by which behavioral information is encoded into serotonergic signaling relayed to the SCN (and possibly the IGL). This model is based on the present findings that (1) DRN-mediated SCN 5-HT release induced by electrical stimulation, GABA antagonist microinjection, or behavioral activation is blocked by intra-DRN or intra-MRN administration of $5-\mathrm{HT}_{7}$ receptor antagonists, indicating that the DRN communicates to the $\mathrm{SCN}$ via a 5 - $\mathrm{HT}_{7}$-sensitive multisynaptic $\mathrm{DRN} \rightarrow \mathrm{MRN} \rightarrow \mathrm{SCN}$ pathway. DRN-stimulated SCN 5-HT release is blocked by intra-MRN injected $5-\mathrm{HT}_{7}$ antagonists, indicating that the MRN is a critical component of this pathway. (2) Intra-DRN or MRN injection of $G A B A_{A}$ antagonist bicuculline stimulate $\mathrm{SCN} 5$-HT release, indicating that raphe activity is tonically suppressed by $\mathrm{GABA}_{A}$ receptor activation. (3) Intra-MRN injection of bicuculline and the $G A B A_{B}$ antagonist 2-hydroxysaclofen (data not shown) equally stimulate $\mathrm{SCN} 5-\mathrm{HT}$ release, indicating that MRN GABA ${ }_{B}$ and $\mathrm{GABA}_{A}$ receptors regulate $\mathrm{SCN} 5-\mathrm{HT}$ release. (4) Electrical DRN stimulation induces 5-HT release in the MRN. This model proposes that behavioral activation suppresses the activity of GABA (1) neurons that tonically inhibit DRN 5-HT (1) neurons (and may also directly activate these 5-HT neurons). The 5-HT (1) neurons, when activated, inhibit DRN and MRN GABA ( 2 and 3 ) neurons that tonically suppress MRN 5-HT (2) neurons expressing both $G A B A_{A}$ and $G A B A_{B}$ receptors. Output from the stimulated 5-HT (1) neurons may also induce release of 5-HT in the IGL. The ensuing activation of the MRN 5-HT (2) neurons causes release of 5-HT from SCN terminals, according to the strength of the behavioral stimulus. This scheme does not rule out the possibility that behavior could also directly stimulate $M R N$ activity. $5-H_{7} R, 5-H T_{7}$ receptor; $G A B A_{A} R$, $G A B A_{A}$ receptor; $G_{A B A_{B}} R, G A B A_{B}$ receptor; - , inhibition; + , activation.

associated with increased GABA release, and this reduction is reversed by bicuculline (Levine and Jacobs, 1992; Nitz and Siegel, 1997; Gervasoni et al., 2000). The suspected regulatory actions of raphe GABAergic transmission in SCN 5-HT release and the timing of the sleep-wake cycle have important implications for circadian phase regulation. Notably, behavior-related changes in raphe GABAergic activity could underlie the circadian phaseresetting effects of sleep deprivation (Antle and Mistlberger, 2000). During the day, when SCN 5-HT release is low (Dudley et al., 1998), there is strong GABAergic inhibition of raphe activity associated with the sleep state (discussed above). In the proposed model in Figure 9, sleep deprivation-induced SCN 5-HT release (Grossman et al., 2000) is attributed to a behavior-arousal- mediated suppression of DRN GABAergic tone. The potentiated 5 -HT output may in turn mediate behaviorally induced phase resetting. This model is supported by the present findings that (1) 5 -HT release at midday is stimulated by bicuculline, and (2) this release is blocked by intra-DRN injection of metergoline, as is sleep deprivation-induced SCN 5-HT release. It is possible that the circadian phase-related actions of intra-DRN GABA involve the same $\mathrm{GABA}_{\mathrm{A}}$-benzodiazepine receptor population responsible for mediating the phase-resetting effects of triazolam (Turek and Losee-Olson, 1986; Turek and Van Reeth, 1988; Van Reeth and Turek, 1989; Marchant and Morin, 1999). However, it is unlikely that the DRN is a target for the phase-shifting action of triazolam (Meyer-Bernstein and Morin, 1998; Marchant and Morin, 1999), and triazolam and behavioral stimuli do not act via the same phase-resetting mechanism (Meyer-Bernstein and Morin, 1998; Janik and Mrosovsky, 1992; Marchant and Morin, 1999).

\section{DRN modulation of behavioral phase resetting}

Intra-DRN treatments with DR4004 or muscimol at dosages that suppress DRN signaling to the SCN significantly attenuated the phase-advancing effect of novel wheel access. Notably, the mean shifting response of the drug-treated animals running at or more than the 400-500 revolution range was only $\sim 30 \%$ of maximally shifting vehicle controls running with similar exertion. It is therefore apparent that inhibiting DRN output can attenuate behavioral phase shifting, which is not caused by drug-related suppression of running activity. As discussed above, we propose that DR4004 and muscimol inhibit different components of the DRN pathway(s) that participate in phase resetting. Namely, DR4004 treatment inhibits the $5-\mathrm{HT}_{7}$ receptor-sensitive component of the DRN system for conveying behaviorally coded serotonergic input to the SCN. The muscimol treatment overrides an inhibitory influence of behavior over the $\mathrm{GABA}_{\mathrm{A}}$ receptor-mediated suppression of DRN serotonergic activity. The actions of both drugs inhibit DRN output to a similar extent, resulting in a suppressed behavioral phase-shifting response. It is notable that the intra-DRN drug treatments attenuated, but did not abolish, phase shifting, indicating that either DRN output was incompletely blocked by the drugs or that behavioral shifting can occur without DRN output. The latter possibility is supported by the finding that hamsters with 5 -HT-specific neurotoxic lesioning of the DRN also can undergo novel wheelinduced phase advances (Meyer-Bernstein and Morin, 1998). Interestingly, previous studies showing that electrical stimulation of the DRN at midday induces phase-advance shifts indicate that DRN output can evoke circadian phase resetting (Meyer-Bernstein and Morin, 1997; Glass et al., 2000). Thus, serotonergic output from the DRN may be sufficient but not necessary for behavioral phase resetting, and its physiological role may be to augment the effects of other neuronal systems mediating clock resetting. The IGL is a good candidate in this regard because it receives serotonergic innervation from the DRN (Meyer-Bernstein and Morin, 1996), and bilateral injection of 8-OH-DPAT in the IGL has a phase-advancing effect (Challet et al., 1998) [although unilateral IGL injection of 8-OH-DPAT is ineffective (Mintz et al., 1997)]. Also, bilateral lesioning of the IGL blocks the phase-shifting effect of peripheral 8-OH-DPAT injection (Schuler et al., 1999), and there is recent evidence that wheel-running at midday induces 5-HT release in the IGL region (J. D. Glass and G. H. Grossman, unpublished observations). 


\section{References}

Albers HE, Ferris CF (1984) Neuropeptide Y: role in light-dark cycle entrainment of hamster circadian rhythms. Neurosci Lett 50:163-168.

Antle MC, Mistlberger RE (2000) Circadian clock resetting by sleep deprivation without exercise in the Syrian hamster. J Neurosci 20:9326-9332.

Antle MC, Marchant EG, Niel L, Mistlberger RE (1998) Serotonin antagonists do not attenuate activity-induced phase shifts of circadian rhythms in the Syrian hamster. Brain Res 813:139-149.

Aschoff J (1965) Response curves in circadian periodicity. In: Circadian clocks (Aschoff J, ed), pp 95-111. Amsterdam: North-Holland.

Biello SM, Janik D, Mrosovsky N (1994) Neuropeptide Y and behaviorally induced phase-shifts. Neuroscience 62:273-279.

Bobrzynska KJ, Mrosovsky N (1998) Phase shifting by novelty-induced running: activity dose-response curves at different circadian times. J Comp Physiol [A] 182:251-258.

Bobrzynska KJ, Vrang N, Mrosovsky N (1996) Persistence of nonphotic phase shifts in hamsters after serotonin depletion in the suprachiasmatic nucleus. Brain Res 741:205-214.

Card JP, Moore RY (1982) Ventral lateral geniculate nucleus efferents to the rat suprachiasmatic nucleus exhibit avian pancreatic polypeptide-like immunoreactivity. J Comp Physiol 206:390-396.

Challet E, Scarbrough K, Penev PD, Turek FW (1998) Roles of suprachiasmatic nuclei and intergeniculate leaflets in mediating the phase-shifting effects of a serotonin agonist and their photic modulation during subjective day. J Biol Rhythms 13:410-421.

Dudley TE, DiNardo LA, Glass JD (1998) Endogenous regulation of serotonin release in the hamster suprachiasmatic nucleus. J Neurosci 18:5045-5052.

Dudley TE, DiNardo LA, Glass JD (1999) In vivo assessment of the midbrain raphe nuclear regulation of serotonin release in the hamster suprachiasmatic nucleus. J Neurophysiol 81:1469-1477.

Duncan MJ, Short J, Wheeler DL (1999) Comparison of the effects of aging on $5-\mathrm{HT}_{7}$ and $5-\mathrm{HT}_{1 \mathrm{~A}}$ receptors in discrete regions of the circadian timing system in hamsters. Brain Res 829:39-45.

Duncan MJ, Temel S, Jennes L (2001) Localization of serotonin 5- $\mathrm{HT}_{7-}$ receptor immunoreactivity in the rat brain. Soc Neurosci Abstr 27:380.18.

Edgar DM, Miller JD, Prosser RA, Dean RR, Dement WC (1993) Serotonin and the mammalian circadian system: II. Phase-shifting rat behavioral rhythms with serotonergic agonists. J Biol Rhythms 8:17-31.

Edgar DM, Reid MS, Dement WC (1997) Serotonergic afferents mediate activity-dependent entrainment of the mouse circadian clock. Am J Physiol 273:R265-R269.

Ehlen JC, Grossman GH, Glass JD (2001) In vivo resetting of the hamster circadian clock by $5-\mathrm{HT}_{7}$ receptors in the suprachiasmatic nucleus. J Neurosci 21:5351-5357.

Gallager DW, Aghajanian GK (1976) Effect of antipsychotic drugs on the firing of dorsal raphe cells. II. Reversal by picrotoxin. Eur J Pharmacol 39:357-364.

Gervasoni D, Peyron C, Rampon C, Barbagli B, Chouvet G, Urbain N, Fort P, Luppi PH (2000) Role and origin of the GABAergic innervation of dorsal raphe serotonergic neurons. J Neurosci 20:4217-4222.

Glass JD, DiNardo LA, Ehlen JC (2000) Dorsal raphe nuclear stimulation of SCN serotonin release and circadian phase-resetting. Brain Res 859:224-232.

Grossman GH, Mistlberger RE, Antle MC, Ehlen JC, Glass JD (2000) Sleep deprivation stimulates serotonin release in the suprachiasmatic nucleus. NeuroReport 11:1929-1932.

Hendrickson AE, Wagoner N, Cowan WM (1972) An autoradiographic and electron microscope study of retinohypothalamic connections. Z Zellforsch Mikrosk Anat 135:1-26.

Jacobs BL, Fornal CA (1997) Serotonin and motor activity. Curr Opin Neurobiol 7:820-825.

Janik D, Mrosovsky N (1992) Gene expression in the geniculate induced by a nonphotic circadian phase-shifting stimulus. NeuroReport 3:575-578.

Johnson RF, Morin LP, Moore RY (1988) Retinohypothalamic projections in the hamster and rat demonstrated using cholera toxin. Brain Res 462:301-312.

Johnson RF, Moore RY, Morin LP (1989) Lateral geniculate lesions alter circadian activity rhythms in the hamster. Brain Res Bull 22:411-422.

Kikuchi C, Nagaso H, Hiranuma T, Koyama M (1999) Tetrahydrobenzindoles: selective antagonists of the 5- $\mathrm{HT}_{7}$ receptor. J Med Chem 42:533-535.

Klein DC, Moore RM, Reppert SM (1991) Suprachiasmatic nucleus: the minds clock. New York: Oxford.
Levine ES, Jacobs BL (1992) Neurochemical afferents controlling the activity of serotonergic neurons in the dorsal raphe nucleus: microiontophoretic studies in the awake cat. J Neurosci 12:4037-4044.

Lovenberg TW, Baron BM, de Lecea L, Miller JD, Prosser RA, Rea MA, Foye PE, Racke M, Slone AL, Siegel BW, Danielson PE, Sutcliffe JG, Erlander MG (1993) A novel adenylate cyclase-activating serotonin receptor (5$\mathrm{HT}_{7}$ ) implicated in the regulation of mammalian circadian rhythms Neuron 11:449-458.

Marchant EG, Morin LP (1999) The hamster circadian rhythm system includes nuclei of the subcortical visual shell. J Neurosci 19:10482-10493.

Marchant EG, Watson NV, Mistlberger RE (1997) Both neuropeptide Y and serotonin are necessary for entrainment of circadian rhythms in mice by daily treadmill running schedules. J Neurosci 17:7974-7987.

Medanic M, Gillette MU (1992) Serotonin regulates the phase of the rat suprachiasmatic circadian pacemaker in vitro during the subjective day. J Physiol (Lond) 450:629-642.

Meyer-Bernstein EL, Morin LP (1996) Differential serotonergic innervation of the suprachiasmatic nucleus and the intergeniculate leaflet and its role in circadian rhythm modulation. J Neurosci 16:2097-2111.

Meyer-Bernstein EL, Morin LP (1997) Electrical stimulation of either the median or dorsal raphe nucleus blocks light-induced fos expression in the suprachiasmatic nucleus. Soc Neurosci Abstr 23:16.8.

Meyer-Bernstein EL, Morin LP (1998) Destruction of serotonergic neurons in the median raphe nucleus blocks circadian rhythm phase-shifts to triazolam but not to novel wheel access. J Biol Rhythms 13:494-505.

Meyer-Bernstein EL, Blanchard JH, Morin LP (1997) The serotonergic projection from the median raphe nucleus to the suprachiasmatic nucleus modulates activity phase onset, but not other circadian rhythm parameters. Brain Res 755:112-120.

Mintz EM, Gillespie CF, Marvel CL, Huhman KL, Albers HE (1997) Serotonergic regulation of circadian rhythms in Syrian hamsters. Neuroscience 79:563-569.

Mistlberger RE, Antle MC, Glass JD, Miller JD (2000) Behavioral and serotonergic regulation of circadian rhythms. Biol Rhythms Res 31:240-283.

Moga MM, Moore RY (1997) Organization of neural inputs to the suprachiasmatic nucleus in the rat. J Comp Neurol 389:508-534.

Mokler DJ, Morgane PJ, Galler JR (2001) Relations between the median (MRN) and dorsal (DRN) raphe nuclei examined by in vivo microdialysis in the conscious rat. Soc Neurosci Abstr 27:701.14.

Moore RY (1983) Organization and function of a central nervous system oscillator: the suprachiasmatic nucleus. Fed Proc 42:2783-2789.

Moore RY, Lenn NJ (1972) A retinohypothalamic projection in the rat. J Comp Neurol 146:1-14.

Morin LP (1999) Serotonin and the regulation of mammalian circadian rhythmicity. Ann Med 31:12-33.

Morin LP, Pace LA (2001) Serotonergic connections between the midbrain median and dorsal raphe nuclei: a double label, tract tracer study. Soc Neurosci Abstr 27:825.11.

Nitz DA, Siegel JM (1997) Inhibitory amino acid transmission in the dorsal raphe nucleus during sleep-wake states. Am J Physiol 273:R451-R454.

Pan ZZ, Williams JT (1989) GABA- and glutamate-mediated synaptic potentials in rat dorsal raphe neurons in vitro. J Neurophysiol 61:719-726.

Pickard GE (1982) The afferent connection of the suprachiasmatic nucleus of the golden hamster with emphasis on retinohypothalamic projection. J Comp Neurol 211:65-83.

Pickard GE, Belenky M (2000) Subcellular distribution of 5- $\mathrm{HT}_{7}$ receptors in the suprachiasmatic nucleus. Proc Soc Neurosci Abstr 76.39.

Prosser RA, Miller JD, Heller HC (1990) A serotonin agonist phase-shifts the circadian clock in the suprachiasmatic nuclei in vitro. Brain Res 534:336-339.

Prosser RA, Dean RR, Heller HC, Miller JD (1993) Serotonin and the mammalian circadian system: I. In vitro phase-shifts by serotonergic agonists and antagonists. J Biol Rhythms 8:1-16.

Rusak B, Zucker I (1979) Neural regulation of circadian rhythms. Physiol Rev 59:449-526.

Schuhler S, Pitrosky B, Saboureau M, Lakhdar-Ghazal N, Pevet P (1999) Role of the thalamic intergeniculate leaflet and its 5-HT afferences in the chronobiological properties of 8-OH-DPAT and triazolam in Syrian hamster. Brain Res 849:16-24.

Shibata S, Tsuneyoshi A, Hamada T, Tominaga K, Watanabe S (1992) Phase-resetting effect of 8-OH-DPAT, a serotonin ${ }_{1 \mathrm{~A}}$ receptor agonist, on 
the circadian rhythm of firing rate in the rat suprachiasmatic nuclei in vitro. Brain Res 582:353-356.

Trulson ME, Jacobs BL (1983) Raphe unit activity in freely moving cats: lack of diurnal variation. Neurosci Lett 36:285-290.

Turek FW, Losee-Olson S (1986) A benzodiazepine used in the treatment of insomnia phase-shifts the mammalian circadian clock. Nature 321:167-168.

Turek FW, Van Reeth O (1988) Altering the mammalian circadian clock with the short-acting benzodiazepine, triazolam. Trends Neurosci 11:535-541.

Van Reeth O, Turek FW (1989) Stimulated activity mediates phase-shifts in the hamster circadian clock induced by dark pulses or benzodiazepines. Nature 339:49-51.
Vertes RP, Kocsis B (1994) Projections of the dorsal raphe nucleus to the brainstem: PHA-L analysis in the rat. J Comp Neurol 340:11-26.

Weber TE, Cato MJ, Rea MA (1998) Electrical stimulation of the median or dorsal raphe nuclei modulate light-induced phase shifts of the circadian wheel-running rhythm of hamsters. Proc Soc Res Biol Rhythms 134:194.

Youngstrom TG, Nunez AA (1986) Comparative anatomy of the retinohypothalamic tract in photoperiodic and non-photoperiodic rodents. Brain Res Bull 17:485-492.

Yu GD, Wei XP, Zhang HQ, Xu S, Yin QZ, Tang PL, Quian ZM (1997) Effects of dorsal raphe nucleus stimulation on unit discharges of lightsensitive neurons of suprachiasmatic nucleus in rats. Acta Physiologica Sinica 49:314-320. 